\title{
Performance of Pitcher Irrigation System
}

\author{
Altaf A. Siyal, ${ }^{1}$ Martinus Th. van Genuchten, ${ }^{2}$ and Todd H. Skaggs ${ }^{3}$
}

\begin{abstract}
Pitcher irrigation is an ancient, but very efficient irrigation system used in many arid and semiarid regions. Small pitchers are often used because they are less expensive than large ones. However, questions exist about whether the patterns and extent of soil wetting obtained with small pitchers are comparable to those achieved with larger pitchers. This work addresses these questions through a combination of experimental and simulation studies involving three pitcher sizes, identified here as large $(20 \mathrm{~L})$, medium $(15 \mathrm{~L})$, and small $(11 \mathrm{~L})$. Saturated hydraulic conductivities of the pitcher materials were measured using a constant head method; the measured values ranged from $0.07 \mathrm{~cm} \mathrm{~d}^{-1}$ for the large pitcher to $0.14 \mathrm{~cm} \mathrm{~d}^{-1}$ for the smaller sizes. To determine the zone of wetting, the pitchers were buried down to their necks in a sandy loam soil and filled with water. Water content distributions were determined after 1 and 10 days at locations 20,40 , and $60 \mathrm{~cm}$ away from the pitcher center at soil depths of $0,20,40$, and $60 \mathrm{~cm}$. Moisture distributions predicted with the HYDRUS-2D simulation model were found to be in close agreement with the experimental results, showing root-mean-square-error values between 0.004 and 0.023 . The close agreement suggests that HYDRUS-2D is a suitable tool for investigating and designing pitcher irrigation systems. Experimental and numerical results showed that a small pitcher half the size of a larger one, but with double the hydraulic conductivity, will produce approximately the same wetting front as the larger pitcher. Simulations for the large pitcher further showed, as expected, more horizontal spreading of water in a fine-texture soil as compared with a coarse-texture soil.
\end{abstract}

Key words: Pitcher irrigation, wetting zone, hydraulic conductivity, HYDRUS-2D.

(Soil Sci 2009;174: 312-320)

$\mathrm{T}_{\mathrm{g}}^{\mathrm{h}}$ he dramatic increase in world population has resulted in greater demand for food and fiber. Meeting the growing demand requires optimizing agricultural production per unit volume of water application (Theib and Ahmed, 2004), particularly in arid and semiarid regions of the world. Although modern irrigation methods such as sprinkler and subsurface drip systems may save up to about half of the water presently used for irrigation, technical, economic, and sociocultural factors hinder the adoption of these technologies. Thus, developing traditional, low-cost, water-saving technologies for sustainable crop production, particularly in semiarid and arid areas, remains a major challenge in science and engineering, one that has been ignored by most international developmental programs

\footnotetext{
${ }^{1}$ Department of Land and Water Management, Sindh Agriculture University, Tandojam, Pakistan;

${ }^{2}$ Department of Mechanical Engineering, Federal University of Rio de Janeiro, UFRJ, Rio de Janeiro, RJ, Brazil. Dr. van Genuchten is corresponding author. E-mail: rvangenuchten@yahoo.com

${ }^{3}$ U.S. Salinity Laboratory, USDA, ARS, Riverside, CA

Received January 8, 2009, and in revised form April 8, 2009.

Accepted for publication April 8, 2009.

Copyright (C) 2009 by Lippincott Williams \& Wilkins, Inc.

ISSN: 0038-075X

DOI: $10.1097 /$ SS.0b013e3181a97532
}

(Bainbridge, 2001). A notable example of such a neglected traditional method is pitcher irrigation.

Pitcher irrigation is an ancient irrigation method thought to have originated in Northern Africa and Iran (Stein, 1998). Pitcher irrigation has been mentioned in a book written some 2000 years ago in China (Sheng, 1974). The method reportedly has been used to irrigate watermelons in India and Pakistan (Mondal, 1974; Soomro, 2002); horticultural crops in Brazil, Germany, and Indonesia (Stein, 1997; Setiawan et al., 1998); and corn, tomato, and okra in Zimbabwe (Batchelor et al., 1996).

Thus far, little research has been carried out on the performance of pitcher irrigation systems, including the various factors affecting water seepage out of the pitchers. The rate of water flow seeping out of a pitcher and thus the number of plants that can potentially be irrigated by the pitcher are affected by, among other things, the saturated hydraulic conductivity of the pitcher material, pitcher wall thickness, pitcher surface area, soil type, crop type, and the rate of evapotranspiration. Stein (1998) found that the hydraulic conductivity of the pitcher material was the most important of three design factors influencing the flow of water through the pitcher wall, followed by the surface area of the pitcher and the wall thickness. For successful design, installation, and operation of pitcher irrigation systems in arid and semiarid regions, pitchers should be placed at suitable distances from each other so that the wetted areas do not needlessly overlap, while at the same time ensuring that areas of the soil root zone are not unintentionally left dry.

In Pakistan and other places, large pitchers cost more than small pitchers, and thus, the size of a pitcher affects start-up and installation costs. To minimize costs, it would thus be beneficial to use small pitchers for irrigation. The question then arises whether small pitchers are capable of producing soil wetting patterns that are comparable to those produced by larger pitchers. This article presents a combination of experimental

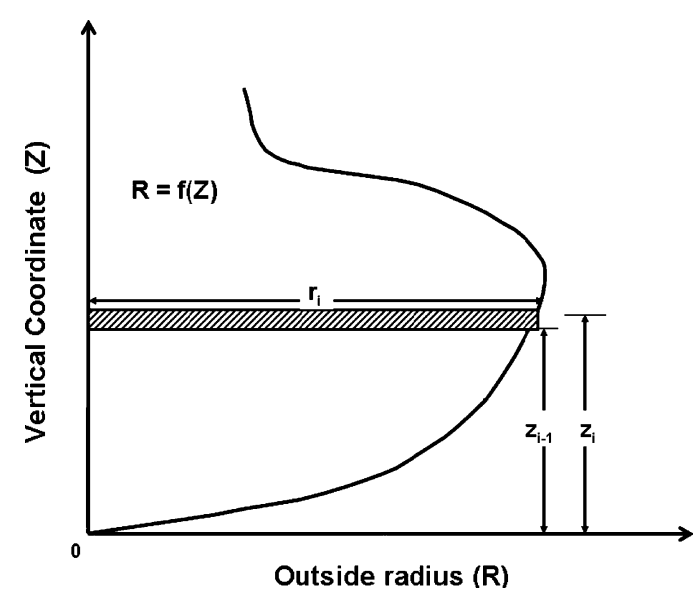

FIG. 1. Illustration of method used to calculate pitcher surface area. 
TABLE 1. Summary of the Physical Characteristics (With SDs) of the Pitchers Used in This Study

\begin{tabular}{lcccccc}
\hline Pitcher Name & Volume $(\mathbf{m L})$ & Height $\mathbf{( c m )}$ & $\begin{array}{c}\text { Mouth } \\
\text { Diameter } \mathbf{( c m )}\end{array}$ & $\begin{array}{c}\text { Wall } \\
\text { Thickness }(\mathbf{c m})\end{array}$ & $\begin{array}{c}\text { Surface } \\
\text { Area }\left(\mathbf{c m}^{\mathbf{2}}\right)\end{array}$ & $\begin{array}{c}\text { Hydraulic Conductivity } \\
\left.\mathbf{( c m ~ d ~}^{-\mathbf{1}}\right)\end{array}$ \\
\hline Large & $19988 \pm 25$ & $31 \pm 0.810$ & $12 \pm 0.410$ & $1.0 \pm 0.100$ & $2710 \pm 140$ & $0.070 \pm 0.001$ \\
Medium & $15025 \pm 35$ & $28 \pm 0.530$ & $11 \pm 0.390$ & $1.0 \pm 0.210$ & $2280 \pm 150$ & $0.076 \pm 0.001$ \\
Small & $11012 \pm 15$ & $25 \pm 0.710$ & $11 \pm 0.511$ & $1.0 \pm 0.200$ & $1840 \pm 200$ & $0.140 \pm 0.004$ \\
\hline
\end{tabular}

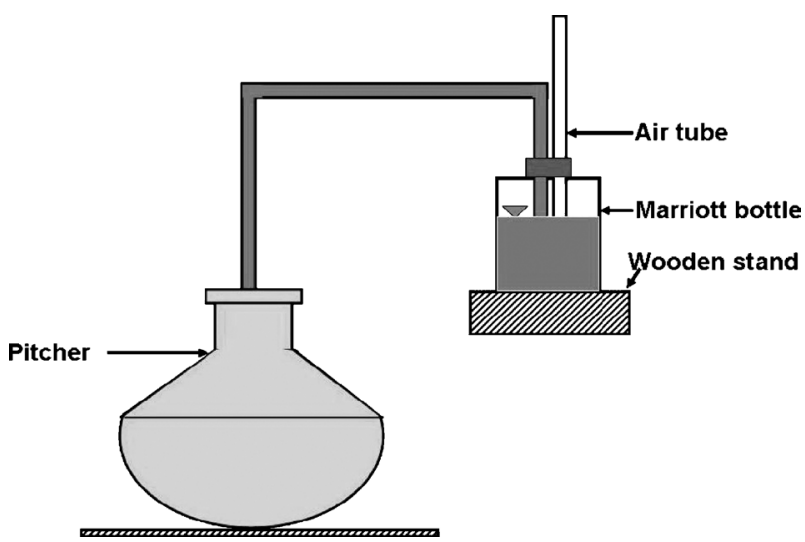

FIG. 2. Schematic of measurement of the saturated hydraulic conductivity of pitchers using the constant head method.

and numerical simulation research that addresses this question. Specifically, we investigate the effect of pitcher size and composition on soil wetting by comparing the performance of large pitchers with low hydraulic conductivity to that of smaller pitchers with a higher hydraulic conductivity. Numerical simulation is an effective approach for investigating optimal irrigation practices, for example, by comparing different irrigation scenarios before implementing them (Powis, 2002; Skaggs et al., 2004). In this article, we compare HYDRUS-2D



FIG. 3. Typical geometry and finite element mesh used for the HYDRUS-2D simulations.
(Simunek et al., 1999) simulations of pitcher seepage with experimental data for three different-size pitchers and assess the utility of using simulation to design and manage pitcher irrigation practices. We note that in a recent article, Zhang et al. (2007) also used HYDRUS-2D to study infiltration from a completely buried pitcher into an Andisol. They obtained good agreement between measured and calculated infiltration rates obtained for different supply pressures, and between measured and calculated soil-moisture contours around the pitcher in the laboratory-scale experiments.


FIG. 4. Measured and predicted water contents for irrigation from the large pitcher, 1 day after initiating irrigation. The upper plot shows the predicted water content contour map, whereas the lower plots compare measured (solid circles) and predicted (solid line) water contents along selected vertical transects. 


\section{METHODS AND MATERIALS}

\section{Pitcher Types}

Field trials were carried out at the experimental site of Sindh Agriculture University in Tandojam, Pakistan. A skilled potter from that area was asked to prepare pitchers of three different sizes, with the small pitchers being more porous than the large ones. The pitchers were made of clay and fired in a kiln; the potter knew how to alter the porosity and permeability of the pitchers by mixing donkey dung or rice husks with the clay. Three sizes of pitchers (having different volumes) were produced. They are identified here as large $(20 \mathrm{~L})$, medium $(15 \mathrm{~L})$, and small $(11 \mathrm{~L})$. Each pitcher size was replicated four times. Pitcher heights on average ranged from $25 \mathrm{~cm}$ (small) to $31 \mathrm{~cm}$ (large). Physical properties of the pitchers are summarized in Table 1.

The thicknesses of the pitcher walls (L) were determined by breaking up three pitchers from each category at the end of experiment and measuring the thickness of the broken pieces with a Vernier caliper. The surface area of each pitcher was calculated by plotting its actual surface curvature as a function of height, as shown in Fig. 1. This was done by first using chalk to draw the outer pitcher circumference. The radii of the outer surface at different heights were then measured using thread. The surface area of each incremental height, and therefore of the entire pitcher, was calculated by integration using:

$$
\begin{gathered}
a_{i}=2 \pi r_{i}\left(z_{i}-z_{i-1}\right) \\
A=\sum_{i=1}^{n} a_{i}
\end{gathered}
$$

where $a_{i}$ is the surface area of the $i^{\text {th }}$ segment $\left(\mathrm{L}^{2}\right), r_{i}$ is the external radius of the $i^{\text {th }}$ segment, $z_{i}$ is the height of the $i^{\text {th }}$ segment above the base of the pitcher, $n$ is the number of segments, and $A$ is the total surface area of the pitcher $\left(\mathrm{L}^{2}\right)$.

\section{Pitcher Hydraulic Conductivities}

The saturated hydraulic conductivities of the pitcher materials were measured using the constant head method as described by Abu-Zreig and Atoum (2004). Following this method, a pitcher was filled with water and placed on top of a flat surface. Water seeped from the pitcher while a constant head condition was maintained with a Marriotte bottle, as shown in
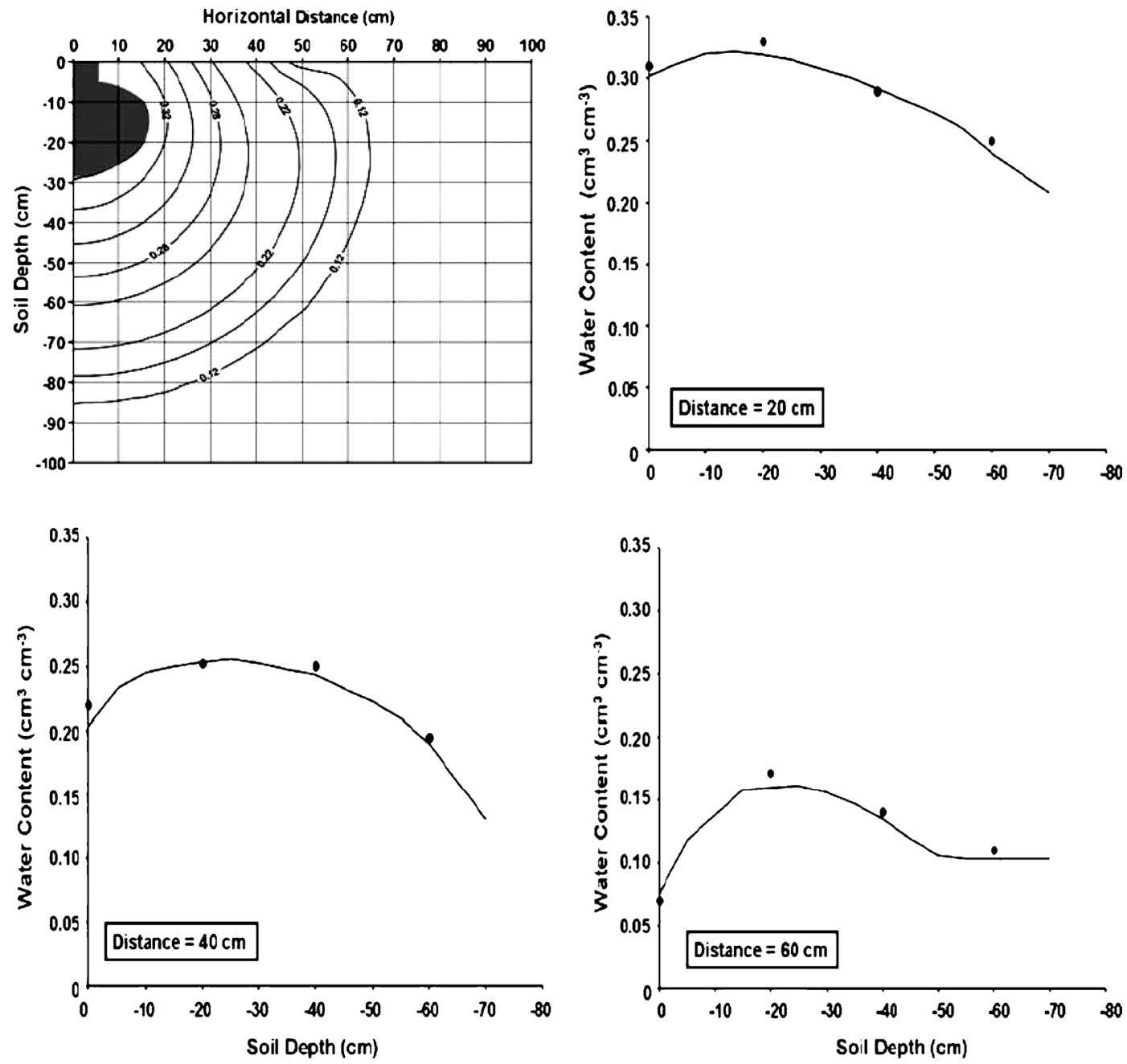

FIG. 5. Measured and predicted water contents for irrigation from the large pitcher, 10 days after initiating irrigation. The upper left plot shows the predicted water content contour map, whereas the lower plots compare measured (solid circles) and predicted (solid line) water contents along selected vertical transects. 
Fig. 2. The daily decrease in the water volume in the Marriotte bottle was assumed to be equal to the daily seepage volume.

The saturated hydraulic conductivity $\left(K_{\mathrm{s}}\right)$ of the pitcher walls was determined by applying Darcy's law to the outflow data. Because the hydraulic head inside the pitcher varied with depth, Darcy's law was applied to the individual pitcher segments and then summed to yield:

$$
Q=\frac{K_{s}}{L}\left(\sum_{i=1}^{n} a_{i}\left(y_{i}-h_{s}\right)\right)
$$

from which $K_{s}$ can be calculated:

$$
K_{S}=\frac{Q L}{\sum_{i=1}^{n} a_{i}\left(y_{i}-h_{s}\right)}
$$

where $Q$ is the seepage rate $\left(\mathrm{L}^{3} \mathrm{~T}^{-1}\right), n$ is the number of segments, $y_{i}$ is the average pressure head inside the pitcher at the


FIG. 6. Measured and predicted water contents for irrigation from the medium pitcher, 1 day after initiating irrigation. The upper plot shows the predicted water content contour map, whereas the lower plots compare measured (solid triangles) and predicted (solid line) water contents along selected vertical transects. $i^{\text {th }}$ segment (equal to the depth of the center of the $i^{\text {th }}$ segment below the water level in the pitcher), and $h_{s}$ is the pressure head at outer surface of pitcher $\left(h_{s}=0\right.$ for an atmospheric seepage boundary condition).

\section{Field Installation}

Before burying the pitchers, the top $60 \mathrm{~cm}$ of soil was cultivated to a fine tilth with spade. Cavities for burying the pitchers were dug about three times as wide and two times as deep as the pitchers. Any clods in the excavated soil were broken up. Pitchers of all three sizes (large, medium, small) were buried in the soil down to their necks, with the mouth openings left $2 \mathrm{~cm}$ above the soil surface. To avoid evaporation, the mouths were covered with baked clay lids. The pitchers were refilled to their initial level every $8 \mathrm{~h}$, and the required volume of water recorded. Potential evaporation rates from the soil surface during the study as measured with a pan evaporimeter were found to be approximately $0.4 \mathrm{~cm} \mathrm{~d}^{-1}$.

\section{Soil Sampling and Analysis}

One and ten days after burying the pitchers, soil samples were taken from depths of $0,20,40$, and $60 \mathrm{~cm}$ at distances 20 , 40 , and $60 \mathrm{~cm}$ from the pitcher center. Because of the presumed symmetry of the wetted zone, two samples for each depth and distance were taken from opposite sides of the pitcher and averaged for data analysis. Gravimetric water contents of the soil samples were determined by recording the weight loss after oven drying at $105^{\circ} \mathrm{C}$ for $24 \mathrm{~h}$. The hydrometer method was used to determine the soil particle size distribution. Soil texture (USDA system) was found to be sandy loam, with the sand content ranging from 56 to $69 \%$, silt from 12 to $27 \%$, and clay from 14 to $19 \%$. The soil bulk density was determined at several locations down to $60-\mathrm{cm}$ depth using a core sampler with $1.5-\mathrm{cm}$ diameter. The density measurements ranged from 1.42 to $1.47 \mathrm{~g} \mathrm{~cm}^{-3}$. Because no obvious trend in the bulk density was observed, we used the average value of $1.44 \mathrm{~g} \mathrm{~cm}^{-3}$ to convert gravimetric water content data to volumetric water contents.

\section{Simulated Wetting Patterns}

Water seepage from the buried pitchers into the soil was simulated using the HYDRUS-2D software package (Simunek et al., 1999). Assuming a homogeneous and isotropic soil, axisymmetric unsaturated flow was calculated using the following form of the Richards equation:

$$
\frac{\partial \Theta}{\partial t}=\frac{1}{r} \frac{\partial}{\partial r}\left(r K \frac{\partial h}{\partial r}\right)+\frac{\partial}{\partial z}\left(K \frac{\partial h}{\partial z}\right)+\frac{\partial K}{\partial z}
$$

where $\Theta$ is the volumetric water content $\left(\mathrm{L}^{3} \mathrm{~L}^{-3}\right) ; h$ is the soilwater pressure head (L); $t$ is time (T); $r$ and $z$ are the radial and vertical (positive upward) space coordinates, respectively; and $K$ is the hydraulic conductivity $\left(\mathrm{L} \mathrm{T}^{-1}\right)$. The soil hydraulic properties $\Theta(h)$ and $K(h)$ were described using the functions of van Genuchten (1980):

$$
\begin{gathered}
\Theta(h)=\left\{\begin{array}{cc}
\Theta_{r}+\frac{-\Theta_{r}}{\left(1+|\alpha h|^{n}\right)^{m}} & h<0 \\
\Theta_{s} & h \geq 0
\end{array}\right. \\
K(h)=K_{s} S_{e}^{l}\left[1-\left(1-S_{e}^{1 / m}\right)^{m}\right]^{2}
\end{gathered}
$$

where $\theta_{r}$ and $\theta_{s}$ are the residual and saturated water contents $\left(\mathrm{L}^{3} \mathrm{~L}^{-3}\right)$, respectively; $K_{\mathrm{s}}\left(\mathrm{L} \mathrm{T}^{-1}\right)$ is the saturated hydraulic 
conductivity; $\alpha\left(\mathrm{L}^{-1}\right), n$ (unitless), and $\ell$ are empirical shape parameters; $m=1-1 / n$, and $S_{\mathrm{e}}$ is effective saturation:

$$
\ell=\frac{\Theta-\theta_{r}}{\Theta_{s}-\theta_{r}}
$$

A finite element mesh was created with the axis of symmetry along the left edge (the center of a pitcher). The boundary of the flow domain was rectangular $(100 \times 100 \mathrm{~cm})$, except near the upper left corner where the pitcher was located. The boundary of the mesh there curved inward, following the contour of the pitcher perimeter (Fig. 3). The flow domain comprised two materials, a 1-cm-thick layer along the curved boundary representing the pitcher material, and the remainder of the domain representing the assumed homogeneous soil material. The boundary nodes along the pitcher wall were assigned a constant pressure head, with the pressure head being zero at the height of the water surface in the pitcher and increasing linearly with depth to a maximum at the bottom of the pitcher (equal to the depth of the water in pitcher). The remaining portion of the left boundary was a zero-flux boundary condition (due to symmetry considerations). A constant potential evaporation rate of $0.4 \mathrm{~cm} \mathrm{~d}^{-1}$ was assigned to the soil surface boundary, whereas the bottom boundary was set as free drainage. The flow domain was made large enough to ensure that the assumed no-flow condition on the outer (right) boundary did not affect the simulations.

The soil hydraulic parameters $\left(\Theta_{r}, \Theta_{s}, \alpha, n\right.$, and $\left.\ell\right)$ needed for the simulations were estimated with the Rosetta pedotransfer functions (Schaap et al., 2001), which predict the hydraulic parameters from soil texture and related data. We used the measured soil texture and bulk density data in Rosetta to obtain the following parameter estimates: $\Theta_{r}=0.051, \Theta_{s}=0.403, K_{s}=$ $42.7 \mathrm{~cm} \mathrm{~d}^{-1}, \alpha=0.025 \mathrm{~cm}^{-1}, n=1.45$, and $\ell=0.5$. The initial water content in the soil profile was determined from soil samples taken during installation of the pitchers. In view of those measurements, we assumed that the water content was uniform horizontally and varied only slightly with depth, from $0.100 \mathrm{~cm}^{3} \mathrm{~cm}^{-3}$ at the soil surface to $0.105 \mathrm{~cm}^{3} \mathrm{~cm}^{-3}$ at the bottom of the flow domain $(100 \mathrm{~cm})$. The simulations used the measured $K_{s}$ values for the pitcher materials, which were 0.070 , 0.076 , and $0.140 \mathrm{~cm} \mathrm{~d}^{-1}$ for pitchers large, medium, and small, respectively. The pitcher porosity (and hence $\Theta_{s}$ ) was estimated to be $0.350 \mathrm{~cm}^{3} \mathrm{~cm}^{-3}$. Other pitcher parameters were assumed to be $\theta_{r}=0.042, \alpha=0.000001 \mathrm{~cm}^{-1}, n=1.3$, and $\ell=0.5$. The small value of $\alpha$ ensured that the pitcher material would remain
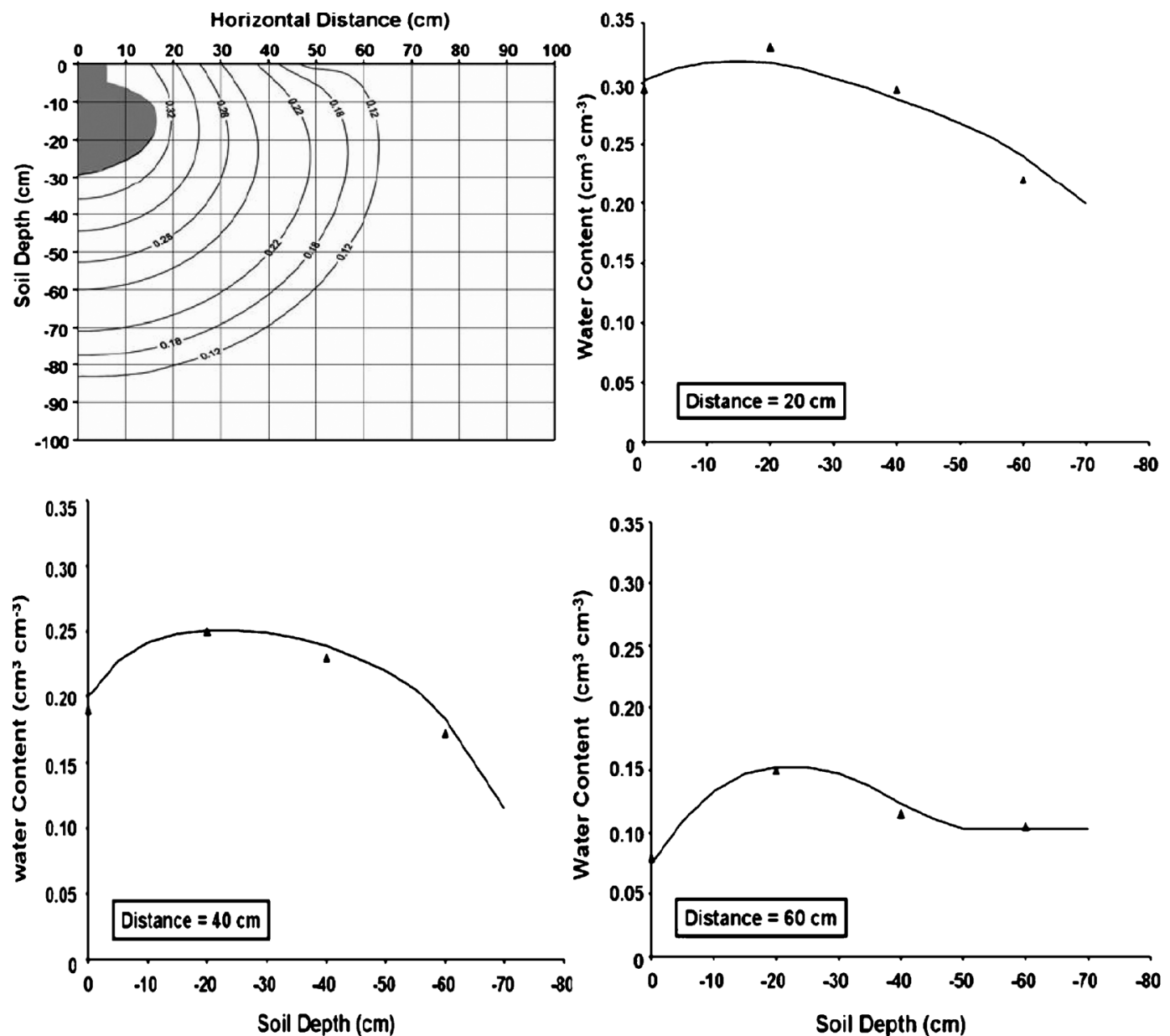

FIG. 7. Measured and predicted water contents for irrigation from the medium pitcher, 10 days after initiating irrigation. The upper plot shows the predicted water content contour map, whereas the lower plots compare measured (solid triangles) and predicted (solid line) water contents along selected vertical transects. 

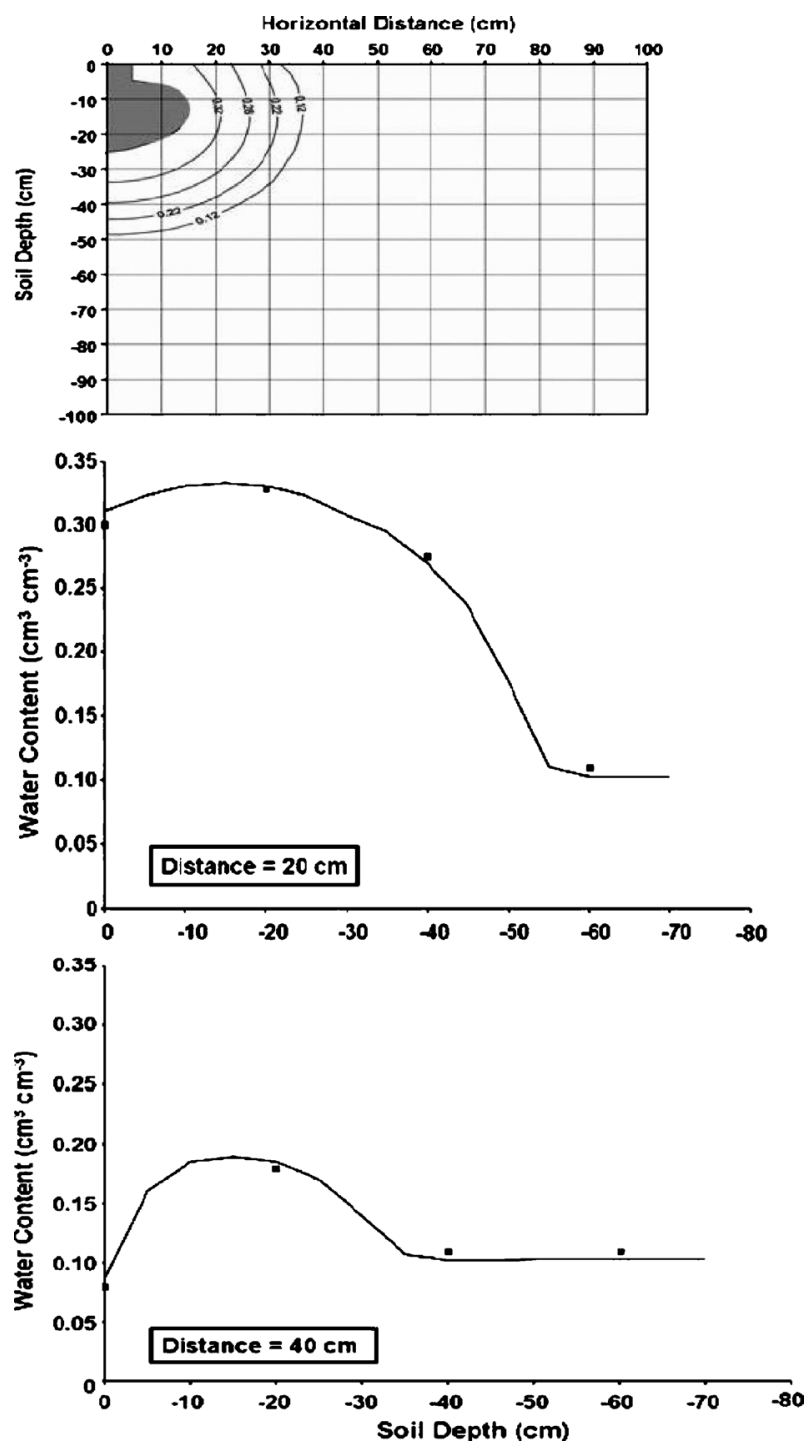

FIG. 8. Measured and predicted water contents for irrigation from the small pitcher, 1 day after initiating irrigation. The upper plot shows the predicted water content contour map, whereas the lower plots compare measured (solid squares) and predicted (solid line) water contents along selected vertical transects.

saturated during the simulations. Hence, $K_{\mathrm{s}}$ was the only parameter of the pitcher material that had a significant impact on the results.

\section{RESULTS AND DISCUSSION}

Figures 4-9 show for the three pitcher sizes measured and simulated moisture distributions obtained 1 and 10 days after initiating irrigation. Each figure shows measured and predicted water content profiles along with selected profile transects, as well as contour plots of simulated water content profiles. The contour plots were drawn using a kriging interpolation algorithm.

The transect plots provide a good comparison between experimental and predicted results. The plots show good agreement $\left(\mathrm{R}^{2}=0.96-0.98\right)$ between the experimental and simulated results. The good agreement is also reflected by the root mean square errors (RMSEs) for the simulated and measured water contents along the vertical transects (Table 2). Root-mean-square-error values range between 0.005 and 0.009 $\mathrm{cm}^{3} \mathrm{~cm}^{-3}$ for the large pitcher, 0.004 and $0.013 \mathrm{~cm}^{3} \mathrm{~cm}^{-3}$ for the medium pitcher, and 0.006 and $0.023 \mathrm{~cm}^{3} \mathrm{~cm}^{-3}$ for the small pitcher. This level of accuracy confirms that HYDRUS-2D simulations are sufficiently accurate to justify using this code to investigate and design pitcher irrigation systems.

The level of accuracy in the predictions is especially noteworthy in view of the invoked water application boundary condition along the pitcher boundary. Previous work by Skaggs et al. (2004) found similarly good agreement between simulated and measured moisture distributions around buried drip irrigation lines. However, in that study, the water application boundary was a flux condition (flux-controlled infiltration) such that it was ensured that the actual and simulated applied water volumes were identical. In this study, we used a constant head condition (profile-controlled infiltration) that causes the infiltration rate to depend on the applied boundary pressure head values, hydraulic conductivity of the pitcher material, unsaturated soil hydraulic properties, and the initial water content of the soil. The good agreement obtained in this study for the more complex profile-controlled infiltration scenario is hence a significant result. This is also in view of the fact that we used soil hydraulic parameters estimated with Rosetta-based pedotransfer functions, rather than direct measurements.

Figure 10 compares observed water contents and, indirectly, the wetted zones produced by the three pitchers 10 days after irrigation at various locations in the soil. The volume of the large pitcher was $25 \%$ greater than that of the medium pitcher, and $45 \%$ greater than that of the small pitcher (see also Table 2). The surface area of the large pitcher was similarly $15 \%$ greater than that of the medium pitcher and $32 \%$ greater than that of the small pitcher. Thus, the medium pitcher was approximately threefourths the size of the large pitcher, whereas the small pitcher was approximately half the size of the large pitcher. On the other hand, the hydraulic conductivity of the medium pitcher was $12 \%$ greater than that of the large pitcher, whereas the conductivity of the small pitcher was twice that of the large pitcher. The results in Fig. 10 show that 10 days after burying the pitchers, a very similar wetting pattern was obtained with the large and medium pitchers. However, the small pitcher produced $40 \%$ higher water content at $60 \mathrm{~cm}$ from the pitcher center, as compared with the large pitcher. Thus, a pitcher half the size of a larger pitcher but with double the hydraulic conductivity can produce soil wetting patterns comparable to those obtained with more expensive larger pitchers. This suggests that for given soil hydraulic conditions, the hydraulic conductivity of the pitcher material is the most important factor determining water flow into the soil, followed by the surface area of the pitcher [consistent with the findings of Stein (1998)]. The large pitcher had low hydraulic conductivity but 15 and $32 \%$ more surface area than the medium and small pitchers, respectively, but it created similar wetting patterns to those of obtained with the small pitcher.

The close agreement between measured and predicted water content distributions in Figs. 4-10 gives much confidence in using HYDRUS-2D to investigate the effects of various pitcher irrigation parameters on resultant soil-moisture distributions. Especially of interest is the effect of soil texture on soil wetting patterns. To study this, we carried out a series of HYDRUS-2D simulations using hydraulic parameter values that are typical of particular soil texture classes (Carsel and Parrish, 1988). Predicted moisture distributions along the soil surface after 10 days of irrigation are plotted in Fig. 11 for nine soil 

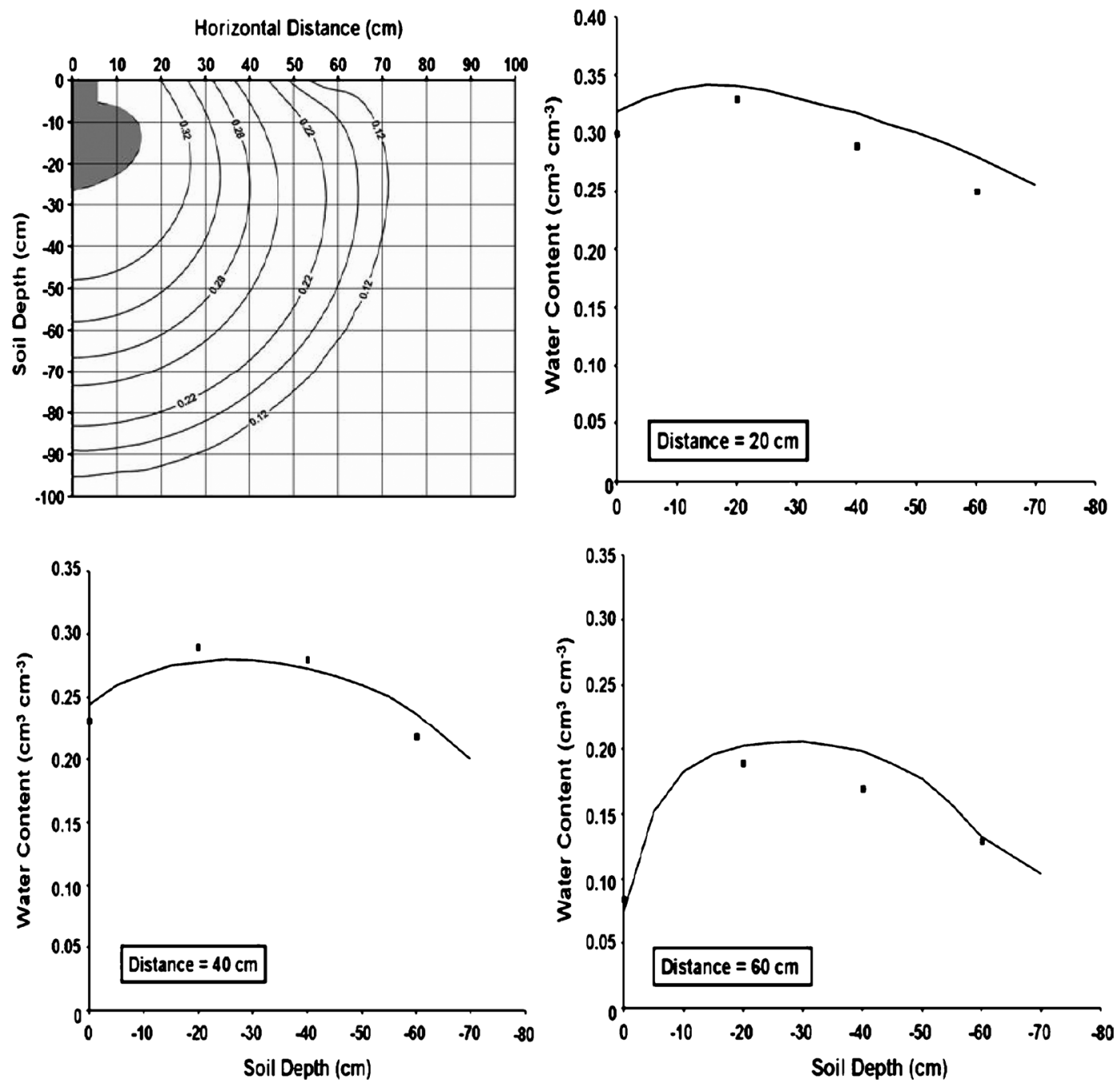

FIG. 9. Measured and predicted water contents for irrigation from the small pitcher, 10 days after initiating irrigation. The upper left plot shows the predicted water content contour map, whereas the lower plots compare measured (solid squares) and predicted (solid line) water contents along selected vertical transects.

textural classes. The figure shows that, as expected, the horizontal spread of the water is larger in the finer-texture soils. By comparison, coarse-texture soils will exhibit much more vertical flow of water as shown by the contour plots in Fig. 12. Results such as those presented in 12 are useful for optimizing pitcher irrigation operational parameters. This pertains not only to the size of the pitcher and the hydraulic conductivity of the pitcher material, but also the spacing of the pitchers relative to each other for a given soil texture, the extent and frequency of refilling, and expected evapotranspiration rates and crop rooting patterns.

\section{SUMMARY AND CONCLUSIONS}

Experimental and numerical studies were carried out to investigate expected wetting patterns and moisture distributions during pitcher irrigation. The experimental and simulation results both showed that similar soil wetting patterns can be achieved with small and large pitchers if the smaller pitcher has a higher hydraulic conductivity than the larger one. Because smaller pitchers are less expensive than larger ones, the use of smaller, higher conductivity pitchers would reduce irrigation equipment costs in arid and semiarid regions using traditional

TABLE 2. Root-Mean-Square-Error Values for HYDRUS-2D Simulated and Measured Data of the Volumetric Water Content at Various Lateral Distances From the Center of the Pitcher Down to a Depth of $60 \mathrm{~cm}$

\begin{tabular}{|c|c|c|c|c|c|c|}
\hline \multirow{3}{*}{$\begin{array}{l}\text { Horizontal } \\
\text { Distance }(\mathrm{cm})\end{array}$} & \multicolumn{6}{|c|}{ Water Content $\left(\mathrm{cm}^{3} \mathrm{~cm}^{-3}\right)$} \\
\hline & \multicolumn{2}{|c|}{$\begin{array}{l}\text { Large } \\
\text { Pitcher }\end{array}$} & \multicolumn{2}{|c|}{$\begin{array}{c}\text { Medium } \\
\text { Pitcher }\end{array}$} & \multicolumn{2}{|c|}{$\begin{array}{c}\text { Small } \\
\text { Pitcher }\end{array}$} \\
\hline & $1 \mathrm{~d}$ & $10 \mathrm{~d}$ & $1 \mathrm{~d}$ & $10 \mathrm{~d}$ & $1 \mathrm{~d}$ & $10 \mathrm{~d}$ \\
\hline 20 & 0.007 & 0.008 & 0.008 & 0.013 & 0.006 & 0.023 \\
\hline 40 & 0.005 & 0.009 & 0.005 & 0.008 & 0.006 & 0.013 \\
\hline 60 & - & 0.007 & - & 0.004 & - & 0.016 \\
\hline
\end{tabular}



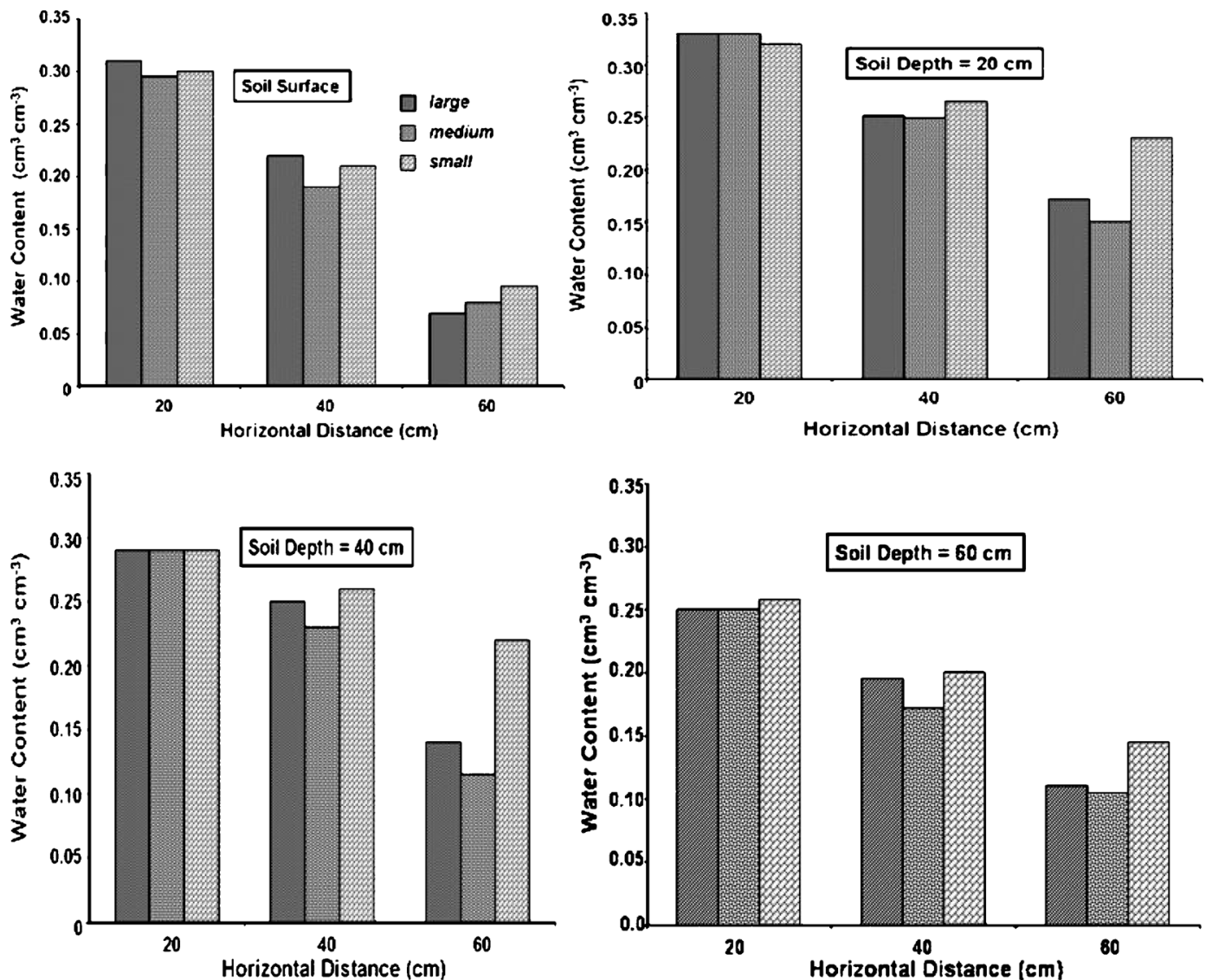

FIG. 10. Comparison of measured water contents at various depths 10 days after initiating irrigation from pitchers having three different sizes and conductivities.

irrigation methods. However, the small pitchers need more frequent refilling, which may require extra labor.

Numerical simulations with the HYDRUS-2D software package were in close agreement with water contents measured during pitcher irrigation of a sandy loam soil (RMSE values ranged from 0.004 to $0.023 \mathrm{~cm}^{3} \mathrm{~cm}^{-3}$ ). These results provide

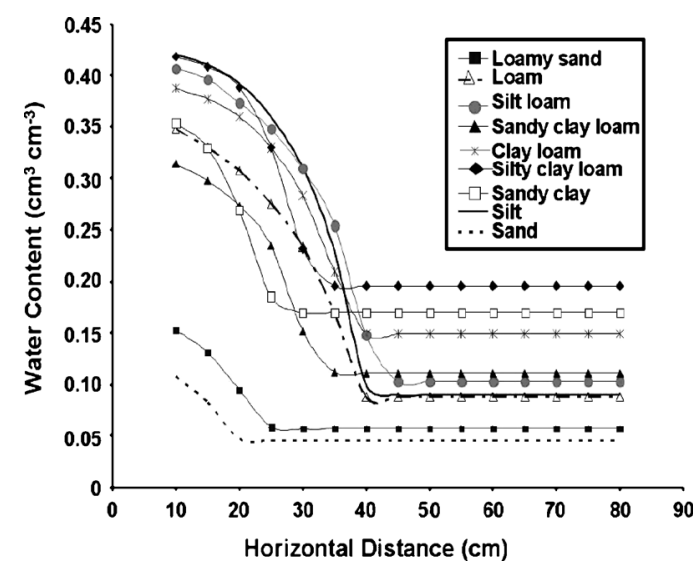

FIG. 11. Predicted water contents along the soil surface for different soil textures, 10 days after initiating irrigation with the large pitcher. support for using HYDRUS-2D as a tool for designing pitcher irrigation systems.

\section{ACKNOWLEDGMENTS}

The Fulbright Foundation is gratefully acknowledged for providing a fellowship to the senior author, as is Sindh Agriculture University, Tandojam, Pakistan, for approving sabbatical leave. This study was supported in part also by CAPES, Brazil.

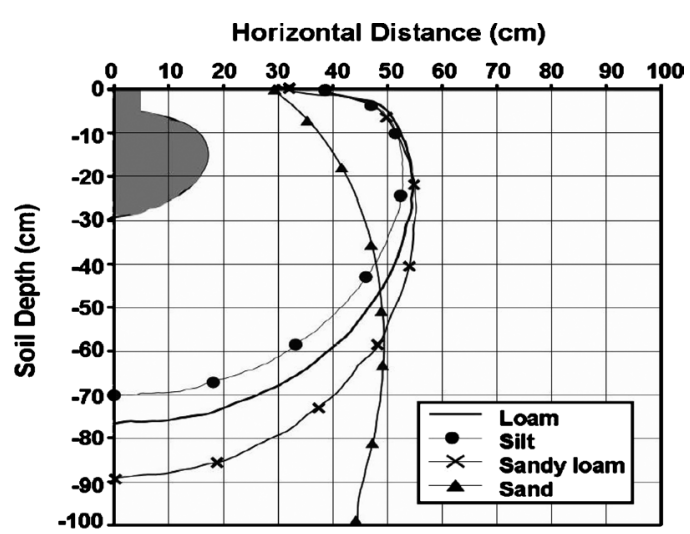

FIG. 12. Predicted water content contours for different soil textures 10 days after initiating irrigation from the large pitcher. 


\section{REFERENCES}

Abu-Zreig, M. M., and F. M. Atoum. 2004. Hydraulic characteristics of clay pitchers produced in Jordan. Can. Biosyst. Eng. 46(1):15-20.

Bainbridge, D. A. 2001. Buried clay pot irrigation: A little known but very efficient traditional method of irrigation. Agric. Water Manag. 48(2): 79-88.

Batchelor, C., C. Lovell, and M. Murata. 1996. Simple microirrigation techniques for improving irrigation efficiency on vegetable gardens. Agric. Water Manag. 32:37-48.

Carsel, R. F., and R. S. Parrish. 1988. Developing joint probability distributions of soil water retention characteristics. Water Resour. Res. 24: 755-769.

Powis, D. 2002. Understanding simulation modeling for the Contact Center. Vanguard Communications Corporation. http://www.vanguard.net/ DocLib_Docs/Simulation_ Modeling_dp_0204.pdf. Accessed May 11, 2009

Mondal, R. C. 1974. Pitcher farming: A simple low-cost method of irrigation. Appropriate Technol. 13:7-8.

Schaap, M. G., F. J. Leij, and M. Th. van Genuchten. 2001. Rosetta: A computer program for estimating Soil hydraulic parameters with hierarchial pedotransfer functions. J. Hydrol. 251:163-176.

Setiawan, B. I., E. Saleh, and Y. Nurhidayat. 1998. Pitcher irrigation system for horticulture in dry lands." Proc. of Water and Land Resources Development and Management for Sustainable Use. Vol. II-A. The Tenth Afro-Asian Regional Conference. ICID- CIID, INACID, DenpasarBali, Indonesia, p 10.

Sheng, H. S. 1974. Fan Sheng-Chih Shu: An Agriculturist Book of China, Written by Fan Sheng-Chih in the First Century BC. Science Books, Beijing, pp. 36-37.
Simunek, J., M. Sejna, and M. Th. van Genuchten. 1999. The HYDRUS-2D software package for simulating the two-dimensional movement of water, heat, and multiple solutes in variably-saturated media. IGWMCTPS 53, Version 2.0, International Ground Water Modeling Center, Colorado School of Mines, Golden, CO.

Skaggs, T. H., T. J. Trout, J. Simunek, and P. J. Shouse. 2004. Comparison of HYDRUS-2D simulations of drip irrigation with experimental observations. J. Irrig. Drain. Eng. 30(4):304-310.

Soomro, A. A. 2002. Viability of pitcher irrigation. Daily Dawn Karachi. 6th May issue. http://www.dawn.com/2002/05/06/ebr12.htm. Accessed on May 11, 2009.

Stein, T. M. 1998. Development and evaluation of design criteria for pitcher irrigation systems. Beiheft No. 66, Selbstverlag des Verbandes der Tropenlandwirte. Witzenhausen e.V., Witzenhausen, ISBN3-88122-971-X.

Stein, T. M. 1997. The influence of evaporation, hydraulic conductivity, wall thickness and surface area on the seepage rates of pitchers for pitcher irrigation. J. Appl. Irrig. Sci. (Zeitschrift für Bewasserungswitrtschaft) 32(1):65-83

Theib, O., and H. Ahmed. 2004. Water harvesting and supplemental irrigation for improved water productivity of dry farming systems in West Asia and North Africa. New directions for a diverse planet. Proceedings of the 4th International Crop Science Congress, September 26-October 1, Brisbane, Australia. Published on CD-ROM. http:// www.cropscience.org.au. Accessed on May 11, 2009.

van Genutchen, M. Th. 1980. A closed-form equation for predicting the hydraulic conductivity of unsaturated soils. Soil Sci. Soc. Am. J. 44:892-898.

Zhang, J., K. Nagasawa, S. Suzuki, T. Nishimura, and M. Toko. 2007. Development of subsurface irrigation technology by utilizing ceramic pitcher. J. Arid Land Studies 17(3):113-121. 